\title{
Yoghurt Consumption Regulates the Immune Cells Implicated in Acute Intestinal Inflammation and Prevents the Recurrence of the Inflammatory Process in a Mouse Model
}

\author{
SILVINA CHAVES, ${ }^{1}$ GABRIELA PERDIGON, ${ }^{1,2}$ AND ALEJANDRA DE MORENO DE LEBLANC ${ }^{1 *}$
}

\begin{abstract}
${ }^{1}$ Centro de Referencia para Lactobacilos, Consejo Nacional de Investigaciones Científicas y Tecnológicas, Chacabuco 145, San Miguel de Tucumán, Tucumán, Argentina T4000ILC; and ${ }^{2}$ Cátedra de Inmunología, Facultad de Bioquimíca, Química, y Farmacia, Universidad Nacional de Tucumán, San Miguel de Tucumán, Tucumán, Argentina
\end{abstract}

MS 10-375: Received 3 September 2010/Accepted 22 November 2010

\begin{abstract}
Crohn's disease and ulcerative colitis, two forms of inflammatory bowel disease, are important problems in industrialized countries. The complete etiology of these two diseases is still unknown but likely involves genetic, environmental, and immunological factors. The aim of the present work was to determine whether the anti-inflammatory effects reported for yoghurt in acute trinitrobenzene sulfonic acid-induced intestinal inflammation in mice also could prevent or attenuate the recurrent intestinal inflammation, thus maintaining remission. The innate response also was evaluated through participation of Toll-like receptors (TLRs) and the analysis of T-cell populations to determine the effects of yoghurt in an acute inflammatory bowel disease model. Yoghurt exerted a beneficial effect on acute intestinal inflammation by regulating T-cell expansion and modulating the expression of TLRs, with decrease of TLR4 ${ }^{+}$and increase of TLR9 ${ }^{+}$cells. The anti-inflammatory effect of yoghurt also was demonstrated in a recurrent inflammation model. Yoghurt administration during the remission phase prevented the recurrence of inflammation without producing undesirable side effects. The yoghurt effect may be mediated by increased interleukin 10 production and changes in intestinal microbiota.
\end{abstract}

Crohn's disease and ulcerative colitis are the two major forms of chronic inflammatory bowel disease (IBD). Although these diseases have some characteristics in common, they also have differences; for example, ulcerative colitis primarily affects the colon and rectum, whereas Crohn's disease usually affects the whole intestinal wall and potentially may extend to the entire gastrointestinal tract (30). The exact cause of IBD is still unknown; however, chronic inflammation probably is a result of aberrant immune response and dysregulated intestinal microbiota in the context of a genetic predisposition (36). Genetic and environmental factors also produce an immunopathogenic process in cases of chronic inflammation with remission periods (5).

Much progress has been made using murine models for characterizing immune cell populations and inflammatory mediators present in patients with IBD. Cytokines (mediators produced by immune cells) are involved in the regulation of cell activation, growth, and differentiation and in the inflammation and immune tolerance and can trigger the differentiation and activation of $\mathrm{T}$ cells. Researchers studying IBD have found that deregulation of $\mathrm{T}$ cells is involved in this pathology. Deletion or apoptosis of over- and autoreactive cells is affected by a imbalance

* Author for correspondence. Tel: 54-381-4310465, Ext 129; Fax: 54381-4005600; E-mail: demoreno@cerela.org.ar. between Treg-Th1, Th2, and Th17 cells in an active state $(23,33)$, whereas the lack of Treg cells or the excessive production of effector $\mathrm{T}$ cells results in the development and exacerbation of IBD.

Researchers have reached a consensus that $\mathrm{CD} 4{ }^{+}$ lymphocytes with the Th1 phenotype are dominant in the mucosa of patients with established Crohn's disease. In contrast, the mucosa in patients with ulcerative colitis is dominated by $\mathrm{CD}^{+}{ }^{+}$lymphocytes with a Th2 phenotype (30). However, new immunological insights implicate Th17 cells in the pathogenesis of Crohn's disease, and therapies in which Th1 and Th17 cells are targets may be important for treating this disease (3). Murine models of IBD have revealed that CD4 T-cell differentiation plays a pivotal role in determining the type of immune response generated in the gut and that distinct cytokine profiles characterize each CD4 T-cell subset (Th1, Th2, Th17, and Treg) $(4,18,26)$.

Probiotics are live microorganisms that confer a health benefit on the host when administered in adequate amounts (10). In recent years, the theory of intestinal dysbiosis as a relevant factor in the pathogenesis of IBD has generated much interest (38). Enterobacteria and Bacteroides species have been implicated as important factors in the observed dysbiosis and in the development and recurrence of IBD $(27,37)$. A reduction in populations of an important member of the Firmicutes, Faecalibacterium prausnitzii, was associated with higher risks of postoperative recurrence 
of ileal Crohn's disease (35). The authors of this article suggested that counterbalancing dysbiosis using $F$. prausnitzii as a probiotic is a promising strategy for Crohn's disease treatment. Thus, the improvement of the intestinal microenvironment equilibrium could be one of the therapeutic approaches for probiotics in IBD. Probiotics can also exert intestinal immunomodulatory activity, regulating the inflammatory response and preventing recurrence of IBD $(11,15,24,25,34)$. Despite these beneficial effects, the exact mechanisms and the molecular pathways by which probiotics reduce experimental IBD are largely unknown.

In previous studies, researchers found that the continuous administration of yoghurt to $\mathrm{BALB} / \mathrm{c}$ mice with trinitrobenzene sulfonic acid (TNBS)-induced acute intestinal inflammation modulated the production of proinflammatory cytokines. Yoghurt administration also produced beneficial changes in the intestinal microbiota, and these changes were maintained, even after TNBS inoculation, when the mice continued to receive yoghurt (6).

The first aim of the present work was to expand the knowledge base concerning the mechanisms by which yoghurt exerts its anti-inflammatory activity and to analyze the regulation of the innate immune response through the participation of Toll-like receptors (TLRs) and changes in CD4 and CD8 T lymphocytes by evaluating the release of cytokines to the intestinal fluid. Because of the potential of recurrences, separated by periods of remission, after the first acute episode of Crohn's disease and in accordance with the results obtained with our acute model of IBD; the second aim was to evaluate whether yoghurt consumption can prevent or attenuate recurrent intestinal inflammation.

\section{MATERIALS AND METHODS}

Experimental groups. Five-week-old female BALB/c mice weighing 25 to $28 \mathrm{~g}$ were obtained from the random-bred colony maintained at the Centro de Referencia para Lactobacilos (CERELA). For the acute inflammation model, mice were divided into five experimental groups: (i) TNBS group, in which the mice received inoculation of TNBS to induce inflammation (ii) yoghurtTNBS-yoghurt group, in which the mice were fed yoghurt for 10 consecutive days (basal yoghurt), inoculated with TNBS, and then fed yoghurt again; (iii) yoghurt-TNBS group, in which the mice were given yoghurt for 10 consecutive days and then inoculated with TNBS to study the effect of yoghurt on the prevention of inflammation; (iv) control group, in which the mice were inoculated with the TNBS vehicle (phosphate-buffered saline [PBS] in 50\% ethanol); and (v) yoghurt control group, in which the mice were fed yoghurt throughout the experiment but were not given TNBS. For the recurrent inflammation model, mice were initially inoculated intrarectally with TNBS to induce inflammation, and after 7 to 9 days mice that had recovered their initial body weight were divided into two experimental groups: (i) TNBSTNBS group, in which the mice did not receive special feeding during the 3 weeks before the second TNBS inoculation, and (ii) TNBS-yoghurt-TNBS group, in which the mice were fed yoghurt for 3 weeks. At the end of the feeding period, the mice of both groups received a second intrarectal inoculation of TNBS.

All groups of animals were fed ad libitum with a balanced diet and were maintained in a room with a 12-h light and 12-h dark cycle at $18 \pm 2{ }^{\circ} \mathrm{C}$. Each experimental group consisted of 20 to 25 mice. All animal protocols were preapproved by the Animal
Protection Committee of the CERELA, and all experiments complied with the current laws of Argentina.

Yoghurt preparation. Simulated commercial yoghurt was freshly prepared and evaluated every day to keep the number of bacteria constant and to avoid variations due to storage. Yoghurt was prepared with a pool of eight Lactobacillus delbrueckii subsp. bulgaricus strains (CRL 861, CRL 863, CRL 864, CRL 866, CRL 869, CRL 871, CRL 872, and CRL 887) and two Streptococcus thermophilus strains (CRL 806 and CRL 807). All bacteria were used from the CERELA culture collection. Pooled strains of both cocci and bacilli were grown in $10 \%$ nonfat milk for $16 \mathrm{~h}$ at $37^{\circ} \mathrm{C}$ and added to pasteurized $10 \%$ nonfat milk at a $1 \%$ concentration (coccus to bacillus ratio was 1:1). After incubation for $16 \mathrm{~h}$ at $37^{\circ} \mathrm{C}$, total number of bacteria in the fermented product was $2 \times$ $10^{9} \mathrm{CFU} / \mathrm{ml}$.

Induction of acute and recurrent intestinal inflammation and feeding procedure. For induction of colitis and recurrent colitis, mice were anesthetized intraperitoneally with a mix of ketamine hydrochloride and xylazine hydrochloride. Each mouse was then inoculated intrarectally with $100 \mu \mathrm{l}$ of a TNBS (Sigma, St. Louis, MO) solution (2 mg per mouse) dissolved in 0.01 M PBS (pH 7.4) and mixed with an equal volume of ethanol. Mice were inoculated once for TNBS-induced acute colitis and twice for recurrent colitis. The TNBS solution was slowly instilled into the colon, and the mice were held in a vertical position for $30 \mathrm{~s}$. Body weight and mortality of mice were recorded every other day.

Sampling procedures and colon histology. In the acute intestinal inflammation model, four samples were obtained from each group: a basal sample on day 0 (just before TNBS inoculation) and samples 3, 7, and 14 days after TNBS inoculation. For recurrent inflammation, two samples were obtained from each group: a basal sample ( 3 weeks after the first TNBS inoculation, the same day as the second TNBS inoculation) and a sample 3 days after the second TNBS inoculation. Three mice for each group were euthanized at each sampling time. The experiments were conducted three times. Mice were euthanized for histological and immunohistochemical evaluations. Serial paraffin-embedded sections $(4 \mu \mathrm{m}$ thick) were made and stained with hematoxylin and eosin for light microscopic examination. For colon histology, the slides were reviewed and the extent of colon damage and inflammation was assessed based on the histopathological grading system of Ameho et al. (2) (Table 1).

Study of the intestinal microbiota. For the recurrent inflammation model, the sample obtained 21 days after the first TNBS inoculation was evaluated. The same technique was previously used in the acute IBD model (6). Serial dilutions of the homogenized samples were obtained and spread onto the surface of the following agarized media: reinforced clostridial agar (RCA; Britania, Buenos Aires, Argentina) for total anaerobic bacteria, RCA containing $0.2 \% \mathrm{LiCl}, 4 \mathrm{mg} /$ liter colistin, and $1 \%$ aniline blue and adjusted to $\mathrm{pH} 5$ with acetic acid for isolation of bifidobacteria, de Man Rogosa Sharpe (MRS; Britania) for total lactobacilli, and MacConkey (Britania) for Enterobacteriaceae. The MacConkey plates were incubated aerobically at $37^{\circ} \mathrm{C}$ for $24 \mathrm{~h}$; all others plates were incubated anaerobically at $37^{\circ} \mathrm{C}$ for 72 to $96 \mathrm{~h}$.

Determination of bacterial translocation to the liver. Bacterial translocation to the liver was investigated for the recurrent IBD model (3 days after the second TNBS inoculation) using the technique described previously (6). 
TABLE 1. Histopathological grading scale of chemically induced colitis

Grade Microscopic findings

0 Histological findings identical to normal mice.

1 Mild mucosal and/or submucosal inflammatory infiltrate (admixture of neutrophils) and edema. Punctate mucosal erosions often associated with capillary proliferation. Muscularis mucosae intact.

2 Grade 1 changes involving 50\% of the specimen.

3 Prominent inflammatory infiltrate and edema (neutrophils usually predominating) frequently with deeper areas of ulceration extending through the muscularis mucosae into the submucosa. Rare inflammatory cells invading the muscularis propriae but without muscle necrosis.

4 Grade 3 changes involving $50 \%$ of the specimen.

5 Extensive ulceration with coagulative necrosis bordered inferiorly by numerous neutrophils and fewer mononuclear cells. Necrosis extends deeply into the muscularis propria.

6 Grade 5 changes involving $50 \%$ of the specimen.

Immunofluorescence assay for $\mathrm{CD}^{+}$and $\mathrm{CD8}^{+} \mathrm{T}$ lymphocytes in the large intestine. Large intestine tissue sections $(4 \mu \mathrm{m})$ from each mouse were used for the immunofluorescence assays. The numbers of $\mathrm{CD} 4^{+}$and $\mathrm{CD} 8^{+} \mathrm{T}$ lymphocytes were determined by direct immunofluorescence assay. Slides were incubated with monoclonal antibodies conjugated with fluorescein isothiocyanate (FITC; Cedarlane, Ottawa, Ontario, Canada). The number of fluorescent cells was counted in 30 fields of vision, as seen at $\times 1,000$ magnification with a fluorescent light microscope. The results were expressed as positive cells in 10 fields of vision.

Determination of $\mathrm{TLR4}^{+}$and $\mathrm{TLR9}^{+}$cells in slices of the large intestine. TLR $4^{+}$and $\mathrm{TLR}^{+}$cells were counted on histological slices from the colon tissue of all experimental mice with acute intestinal inflammation. After deparaffinization, the tissue sections $(4 \mu \mathrm{m})$ were incubated with a $1 \%$ blocking solution of bovine serum albumin and Hanks' balanced saline solution (HBSS) for $30 \mathrm{~min}$ at room temperature. Sections were then washed with HBSS, and rabbit anti-mouse TLR4 or TLR9 polyclonal antibodies (eBioscience, San Diego, CA) were applied for $60 \mathrm{~min}$ at room temperature. Sections were then washed twice with HBSS, treated for 45 min with a dilution of goat anti-rabbit antibody conjugated with FITC (Jackson ImmunoResearch Labs, West Grove, PA) at room temperature, and washed twice with HBSS. The number of fluorescent cells was counted in 30 fields of vision at $\times 1,000$ magnification. Results were expressed as the mean number of fluorescent cells per 10 fields.

ELISAs for cytokines in intestinal fluids. Before histological fixation, intestinal fluids were collected from the large intestines of mice, placed in $1 \mathrm{ml}$ of $0.85 \% \mathrm{NaCl}$, and immediately centrifuged at $5,000 \times g$ for $15 \mathrm{~min}$ at $4^{\circ} \mathrm{C}$. The supernatants were recovered and stored at $-20^{\circ} \mathrm{C}$ until cytokine determinations. OptEIA mouse cytokine enzyme-linked immunosorbent assay (ELISA) kits (BD Bioscience, San Diego, CA) were used to determine the concentration of the cytokines interferon (IFN) $\gamma$ and interleukin (IL) 10. The results are expressed as concentration of each cytokine in the intestinal fluid (picograms per milliliter).

Determination of cytokine-producing cells in histological sections. Tissue sections were used for immunofluorescence assays. Cytokine-positive cells were detected by indirect immunofluorescence in large intestine tissues following the technique described by de Moreno de LeBlanc and Perdigón (8). Rabbit antimouse tumor necrosis factor (TNF) $\alpha$, IFN $\gamma$, and IL-10 antibodies (Peprotech, Inc., Rocky Hill, NJ) and goat anti-mouse IL-17 polyclonal antibody (R\&D Systems, Minneapolis, MN) diluted in saponin-PBS were applied to the sections for $75 \mathrm{~min}$ at room temperature $\left(21^{\circ} \mathrm{C}\right)$. The sections were then treated with a dilution of goat anti-rabbit or rabbit anti-goat antibody conjugated with FITC. The number of fluorescent cells was counted in 30 fields of vision at $\times 1,000$ magnification with a fluorescence light microscope and expressed as the number of positive cells in 10 fields of vision.

Statistical analysis. Statistical analyses were performed using MINITAB 14 software (Minitab, Inc., State College, PA) with an analysis of variance GLM followed by Tukey's posthoc test, and results were considered significant at $P<0.05$. Unless otherwise indicated, all values $(n=15)$ were the means \pm standard deviations (SD) of three independent trials (no significant differences were observed between individual replicates).

\section{RESULTS AND DISCUSSION}

Previous studies using an acute intestinal inflammation model induced by TNBS in BALB/c mice revealed that continuous yoghurt administration (before and after TNBS inoculation) modulated the cytokines IL-12 and IL-17, inducing down-regulation of the immune cells involved in the inflammatory process, and favored IL-10 antiinflammatory cytokine production. In addition to this immunomodulatory capacity, another possible mechanism by which the test yoghurt exerted the anti-inflammatory activity was through beneficial changes in the intestinal microbiota with increases in the populations of bifidobacteria and lactobacilli (6).

In the present study with the same murine model, the effect of yoghurt consumption on the T-lymphocyte subtypes and on the innate immune response, based on analysis of TLR expression, was evaluated. The aim was to elucidate the anti-inflammatory mechanisms mediated by yoghurt administration in an acute intestinal inflammatory process.

The overproduction of cytokines resulting from the imbalance of Th1-Th2 immune responses in favor of the Th1 population leads to loss of intestinal homeostasis and can produce chronic intestinal inflammation. In several reports, finding suggest that an exaggerated response by $\mathrm{T}$ cells to antigenic components of the normal microbiota could be one of the triggers for development of IBD.

Effect of yoghurt administration on T lymphocytes, TLR expression, and release of cytokine in the acute IBD model. $\mathrm{CD} 4^{+}$lymphocytes play an important role in the development of IBD (21). $\mathrm{CD}^{+}$lymphocytes are increased and activated in the intestinal lamina propria of IBD patients and in several colitis models. Reconstitution of severe combined immunodeficient mice with functional $\mathrm{CD}^{+}$lymphocytes can lead to a lethal inflammatory colitis. Kappeler and Mueller (19) reported the elevated frequency of activated cytotoxic $\mathrm{T}$ cells and their important role in the pathogenesis of IBD. These activated cytotoxic $\mathrm{T}$ 
FIGURE 1. Effect of TNBS-induced intestinal inflammation and yoghurt feeding on CD4 (A) and CD8 (B) T lymphocytes in the large intestine of mice. Positive cells were counted in histological sections from large intestine of the alcohol control group (diagonal lined bars), the yoghurt group (horizontal lined bars), the yoghurt-TNBS group (dark shaded and diagonal lined bars), the yoghurt-TNBS-yoghurt group (light shaded bars), and the TNBS group (solid bars). Values are the means $\pm S D$ of results for 15 mice from three separate experiments. Means without a common letter differ significantly $(\mathrm{P}<0.05)$.

\section{A}

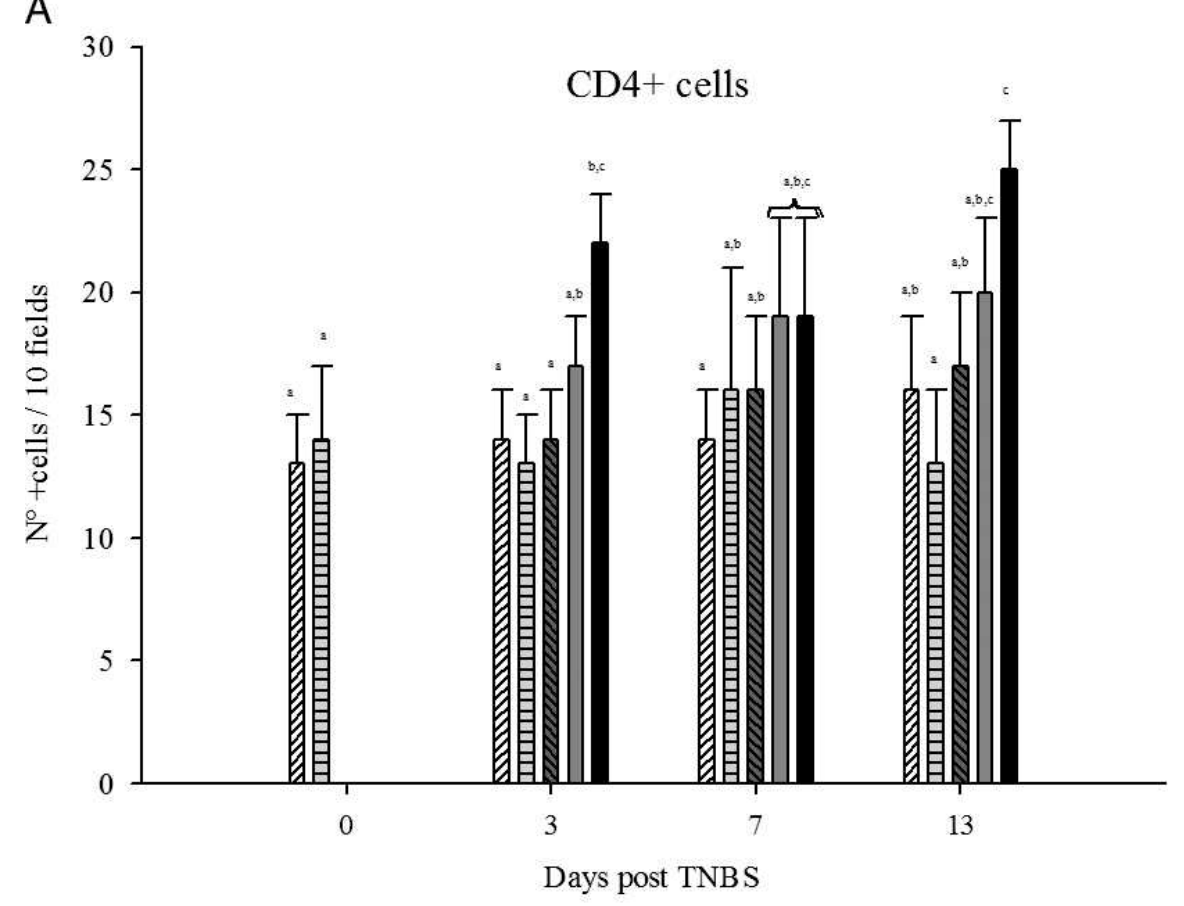

B

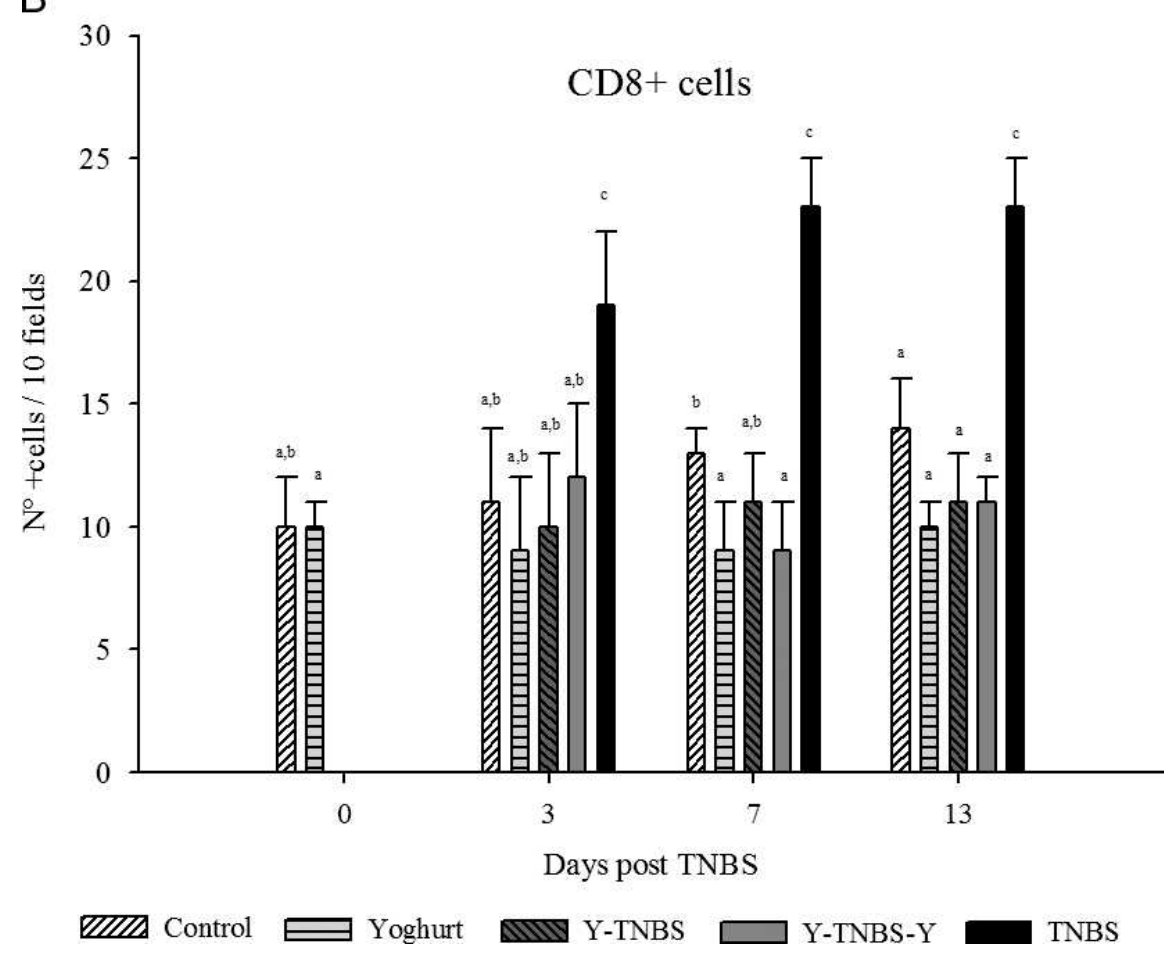

cells exacerbate the inflammatory process through the release of proinflammatory cytokines and chemokines upon lysis of epithelial cells and the increased influx of luminal antigens at the site of epithelial erosions.

In the present study, the intrarectal inoculation of TNBS significantly increased the number of $\mathrm{CD} 4^{+}$and $\mathrm{CD}^{+} \mathrm{T}$ lymphocytes in the TNBS control group. Mice that received the test yoghurt 10 days before TNBS inoculation and continuously before and after TNBS inoculation maintained both T-lymphocyte subtypes at numbers similar to those of the control mice and of mice fed yoghurt but not inoculated with TNBS (Fig. 1).
This finding indicates that yoghurt feeding regulated the T-cell expansion induced by TNBS in agreement with the results of previous studies in which the same yoghurt feeding decreased the number of proinflammatory cytokine producing cells (6), which could be produced by these T cells.

The association of the TLR signaling dysregulation and the pathogenesis of IBD led to consideration of these receptors as therapeutic targets $(16,29)$. Because probiotics and fermented products exert their effects on the immune system mainly through the modulation of innate immunity $(13,14,39)$, in the present study the same acute IBD model 
A

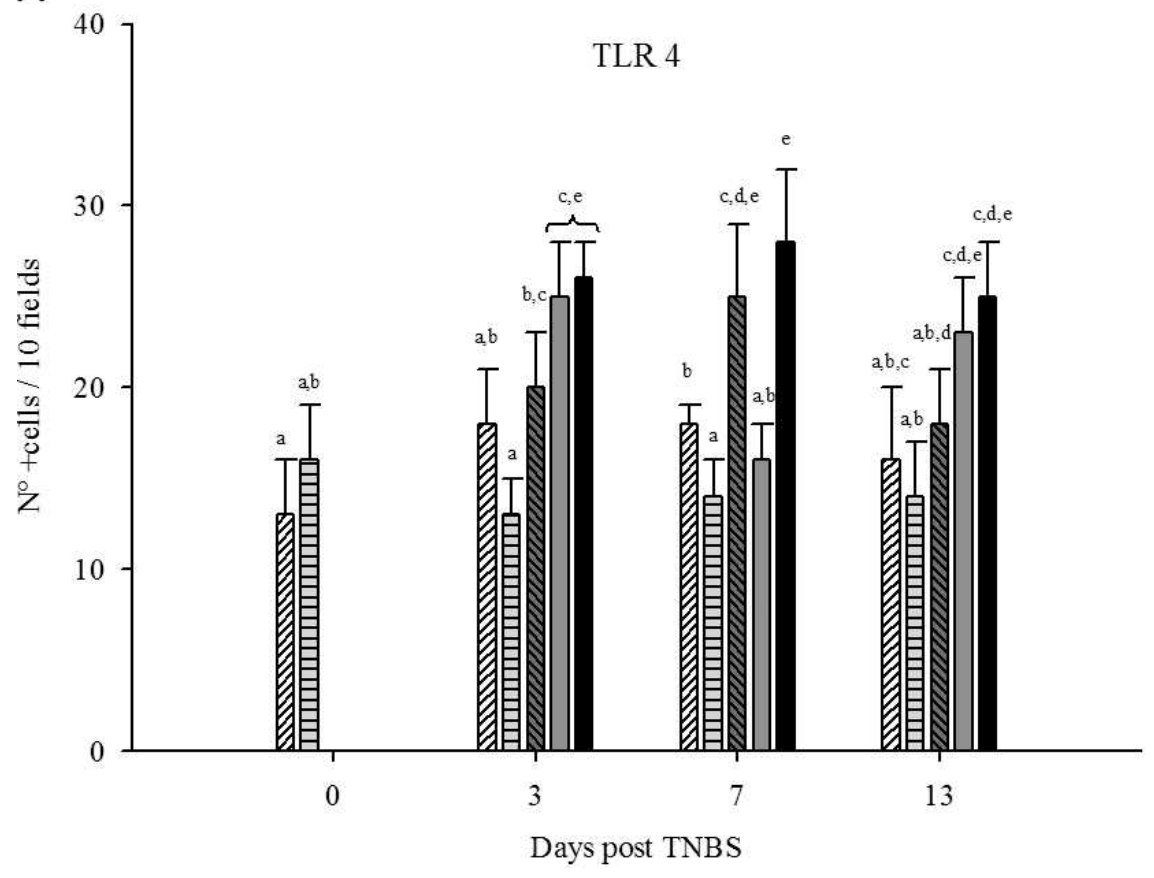

FIGURE 2. Effect of TNBS-induced intestinal inflammation and yoghurt feeding on TLR4 (A) and TLR9 (B) expression in the lamina propria of the large intestine of mice. The effect of yoghurt feeding and TNBS inoculation on the number of $\mathrm{TLR}^{+}$and $\mathrm{TLR}^{+}$cells was determined in the alcohol control group (diagonal lined bars), the yoghurt group (horizontal lined bars), the yoghurt-TNBS group (dark shaded and diagonal lined bars), the yoghurt-TNBS-yoghurt group (light shaded bars), and the TNBS group (solid bars). Values are the means $\pm S D$ of results for 15 mice from three separate experiments. Means without a common letter differ significantly $(\mathrm{P}<0.05)$.

B

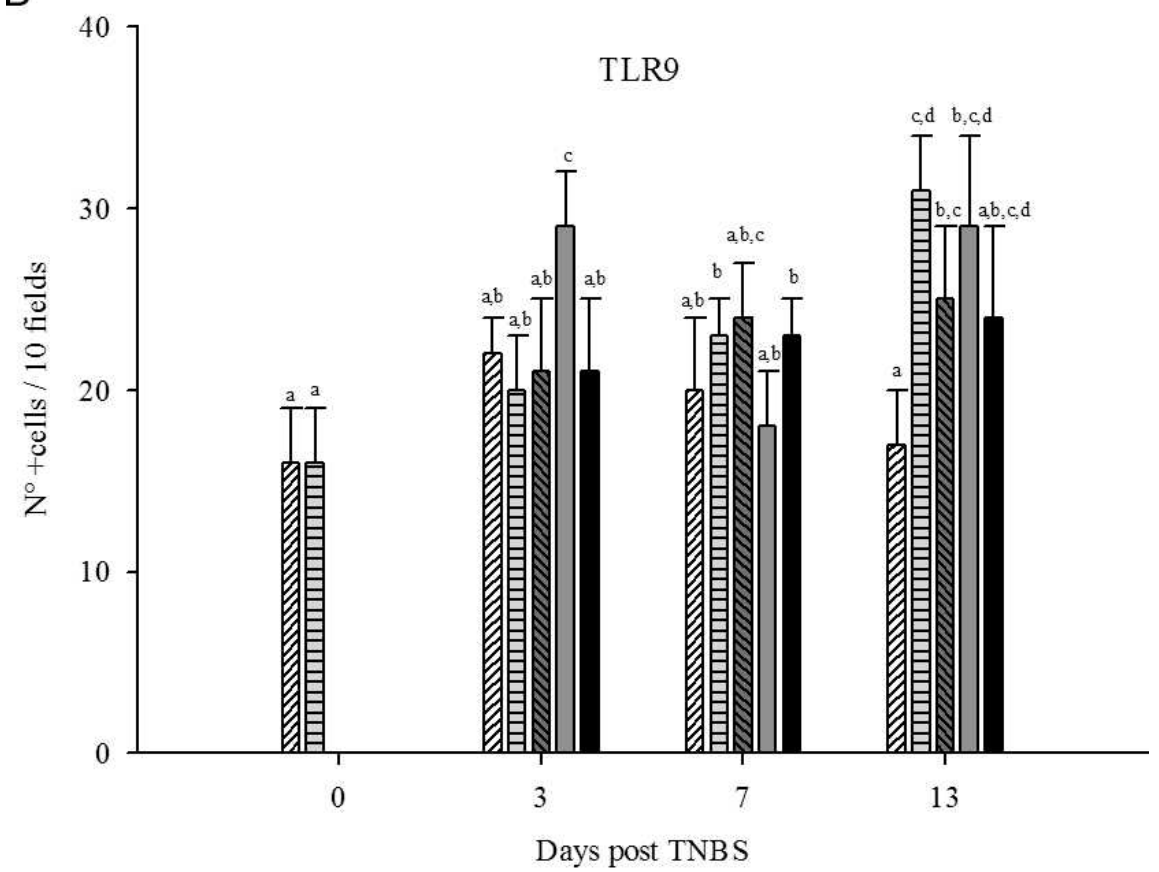

WIIA Control ए Yoghurt $\square$ Y-TNBS $\square$ Y-TNBS-Y $\square$ TNBS

reported previously was used to evaluate the effects of our test yoghurt feeding on the innate immune response, which was analyzed based on TLR expression.

The mechanisms of tolerance of the intestinal epithelium in response to bacterial ligands in the intestinal lumen are mediated by TLRs. TLRs belong to a family of patternrecognizing receptors that detect conserved molecular products of microorganisms, which are emerging as crucial elements in the activation of innate immunity and connectors between innate and acquired immunity. TLR4 was studied because this receptor recognizes the lipopolysaccharides present in the membrane of gram-negative bacteria such as members of the Enterobacteriaceae family, which with other gram-negative bacteria overgrow during an inflammatory process. In the colonic mucosa of IBD patients, large populations of Enterobacteriaceae and Bacteroides were associated with severe inflammation and an increase in TLR4 expression (34). TLR4 is upregulated in both Crohn's disease and ulcerative colitis. Inflammatory cytokines such as IFN $\gamma$ and TNF $\alpha$ increase expression of TLR4 and myeloid differentiation protein 2 , resulting in increased lipopolysaccharide responsiveness (12). 
FIGURE 3. Concentrations of cytokines $I F N \gamma(A)$ and $I L-1 O(B)$ were measured in fluid from the large intestine obtained from mice of the alcohol control group (diagonal lined bars), the yoghurt group (horizontal lined bars), the yoghurt-TNBS group (dark shaded and diagonal lined bars), the yoghurt-TNBS-yoghurt group (light shaded bars), and the TNBS group (solid bars). Values are the means $\pm S D$ of results for 15 mice from three separate experiments. Means without a common letter differ significantly $(\mathrm{P}<0.05)$.
A)

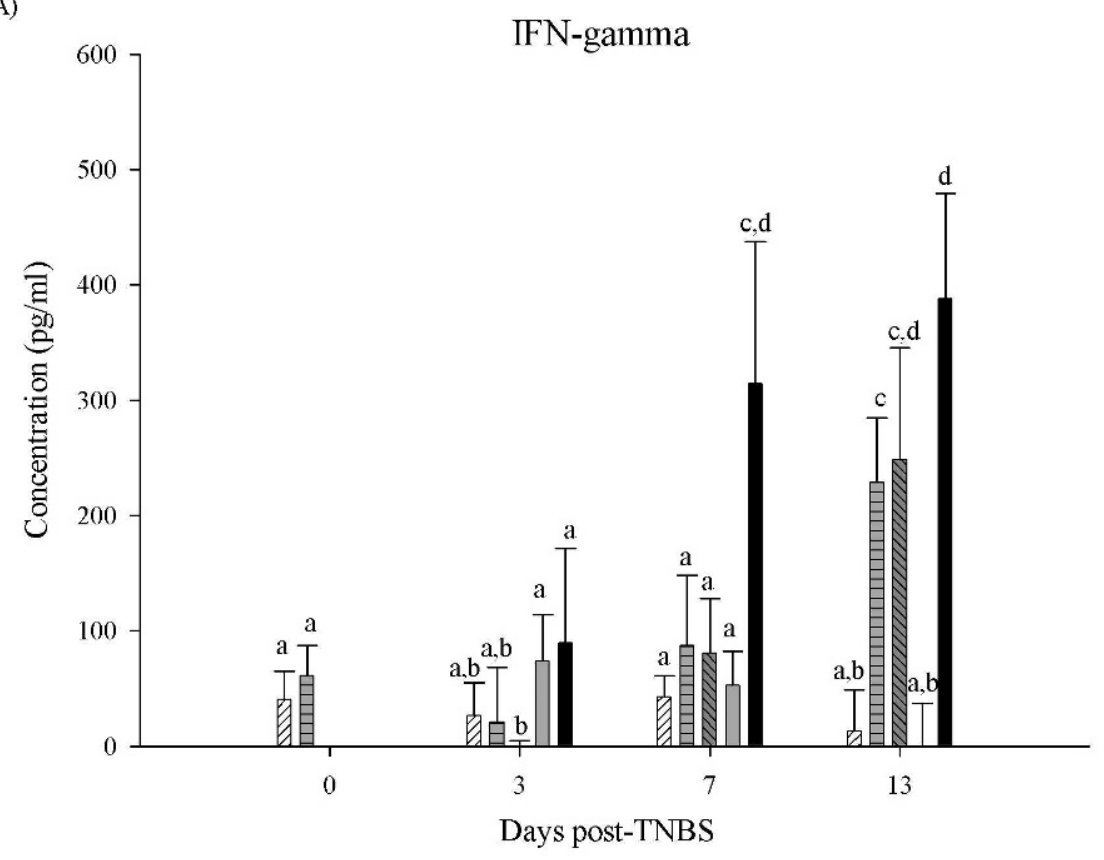

B)

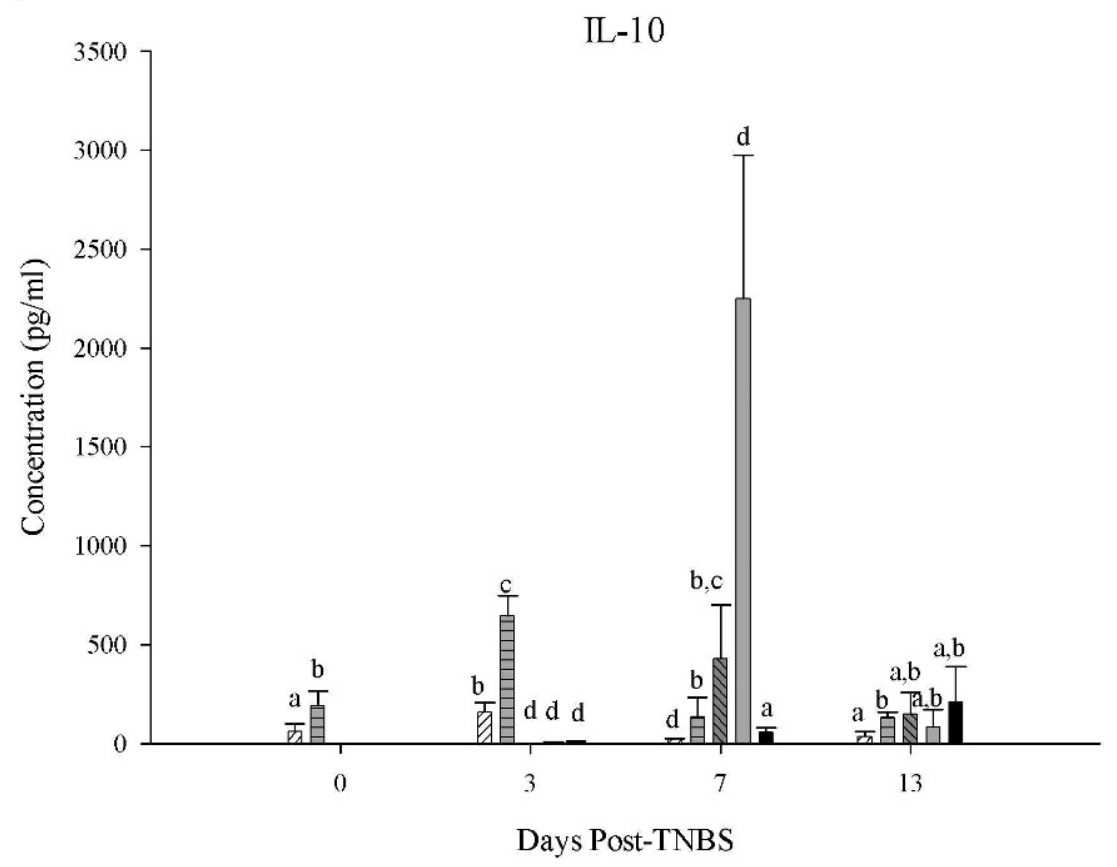

שIIIS Control ए Yoghurt $\square$ Y-TNBS $\square$ Y-TNBS-Y TNBS
In our model, mice fed continuously with the test yoghurt (yoghurt group) did not have modified numbers of $\mathrm{TLR}^{+}{ }^{+}$cells. However, in the TNBS groups, mice that received yoghurt before TNBS inoculation or continuously before and after TNBS inoculation had significantly increased expression of TLR4 at 3 or 7 days post-TNBS, respectively (Fig. 2). Later, these $\mathrm{TLR}^{+}{ }^{+}$cell numbers decreased and were similar to those in the control group at the end of the experimental protocol (14 days post-TNBS), whereas in the TNBS control group $\mathrm{TLR}^{+}$cell numbers stayed high without significant changes during the experiment (Fig. 2).
This decrease in the expression of TLR4 mediated by yoghurt feeding was a desired effect because it is known that TLR4 is related to the severity of the inflammation and is able to trigger the response of the immune cells in a signaling process that culminates with nuclear transcription factor kappa B activation and the consequent cascade of inflammatory cytokines induction. Others have suggested that the development and persistence of inflammation could be prevented by suppressing TLR4 expression in the intestinal epithelial cells (17).

Several studies have revealed that the presence of TLR9 is associated with the beneficial effect exerted by probiotics 

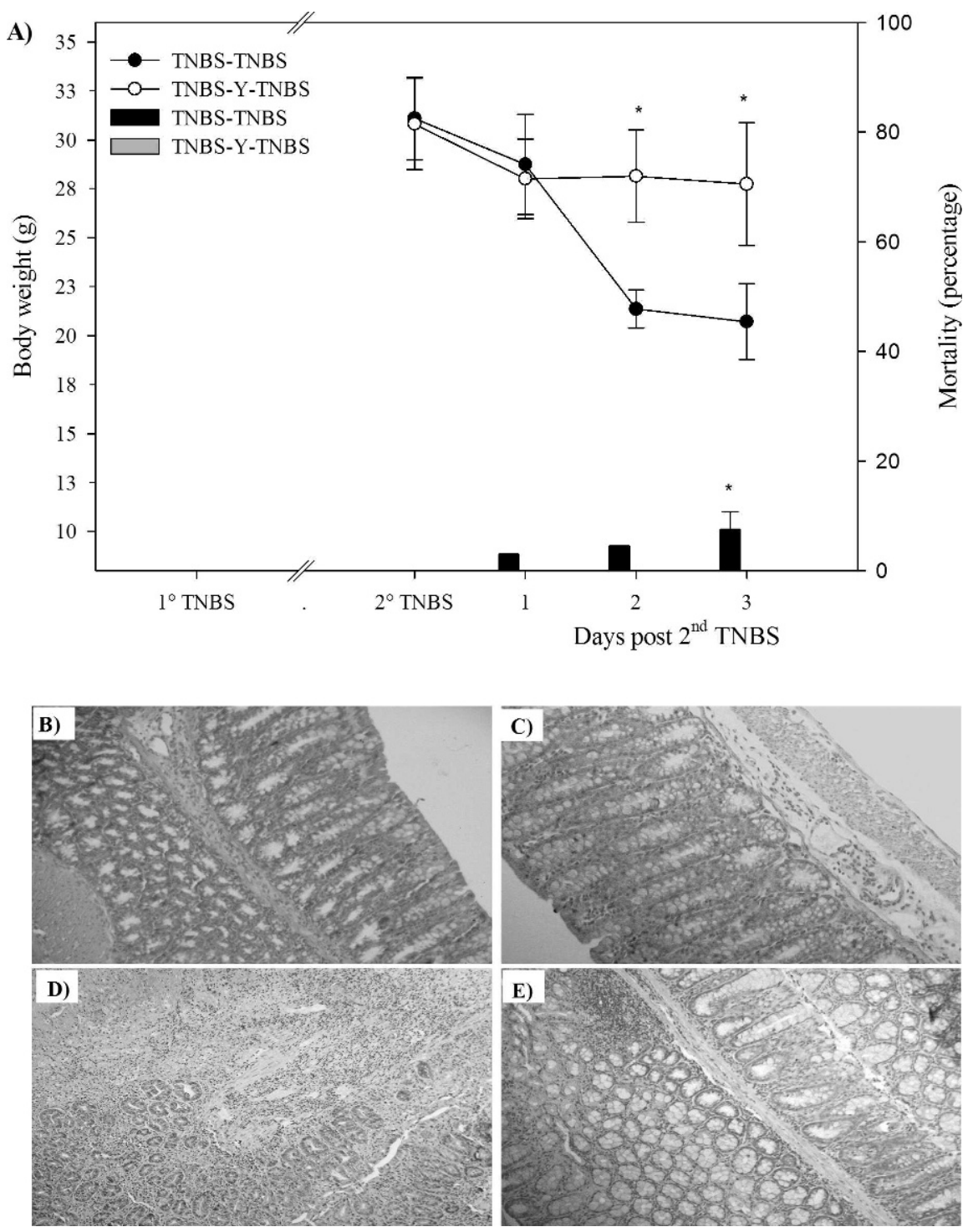

FIGURE 4. Effect of yoghurt feeding during the IBD remission period on body weight, mortality, and histology of the large intestine in mice after the second TNBS inoculation. (A) Weight changes in mice from recurrent intestinal inflammation model (solid line and circle) and mice that received yoghurt feeding before the reinduction of TNBS-mediated intestinal inflammation (solid line and open circle). Mortality was observed only in the recurrent intestinal inflammation model, in which mice were inoculated twice with TNBS: TNBS-TNBS group (solid bars) and TNBSyoghurt-TNBS group (shaded bars). Values are the means $\pm S D$ of results for 15 mice from three separate experiments (each group consisted of at least 5 mice) for each group. Asterisks indicate a significant difference $(\mathrm{P}<0.05)$. The samples for histological evaluation from recurrent intestinal inflammation control mice and mice fed yoghurt were taken 21 days after the first TNBS inoculation and 3 days after the second TNBS inoculation; $\times 100$ magnification. (B) TNBS group. Tissue maintained similar normal structure, although immune cells have infiltrated some areas. (C) TNBS-yoghurt group. Infiltrative cells are visible in the mucosa and submucosa, but an enhanced number of goblet cells and similar normal structure also are present. (D) TNBS-TNBS group. Severe mucosal damage is visible with loss of crypts and focal influx of inflammatory cells in the mucosa and submucosa. Goblet cells also are decreased. (E) TNBS-yoghurt-TNBS group. Large intestine characteristic are similar to those in the TNBS-yoghurt group, with an increased number of goblet and mononuclear cells.

against IBD. Lee et al. (22) reported that the inhibition of experimental colitis by probiotics did not occur in mice deficient in myeloid differentiation primary response gene 88 or TLR9. However, other researchers found that bacterial DNA derived from luminal bacteria contributes significantly to the perpetuation of chronic intestinal inflammation through TLR9. In TLR9-deficient mice the intestinal inflammation was significantly lower and the proinflammatory cytokine production was drastically reduced (28). Intestinal epithelial cells recognize pathogenic bacterial DNA and respond by increasing surface localization and expression of TLR9, suggesting that the inflammatory response to pathogenic DNA is mediated at least in part by increased TLR9 expression that leads to the secretion of IL-8 (1).

In our model of acute inflammation, TLR9 expression increased in the intestinal immune cells of mice fed continuously with yoghurt before and after TNBS inoculation (Fig. 2B). Based on the last sample taken (14 days postTNBS), significantly more TLR9 ${ }^{+}$cells were found in all mice inoculated with TNBS and mice fed continuously with yoghurt in the absence of TNBS compared with the control 
A)

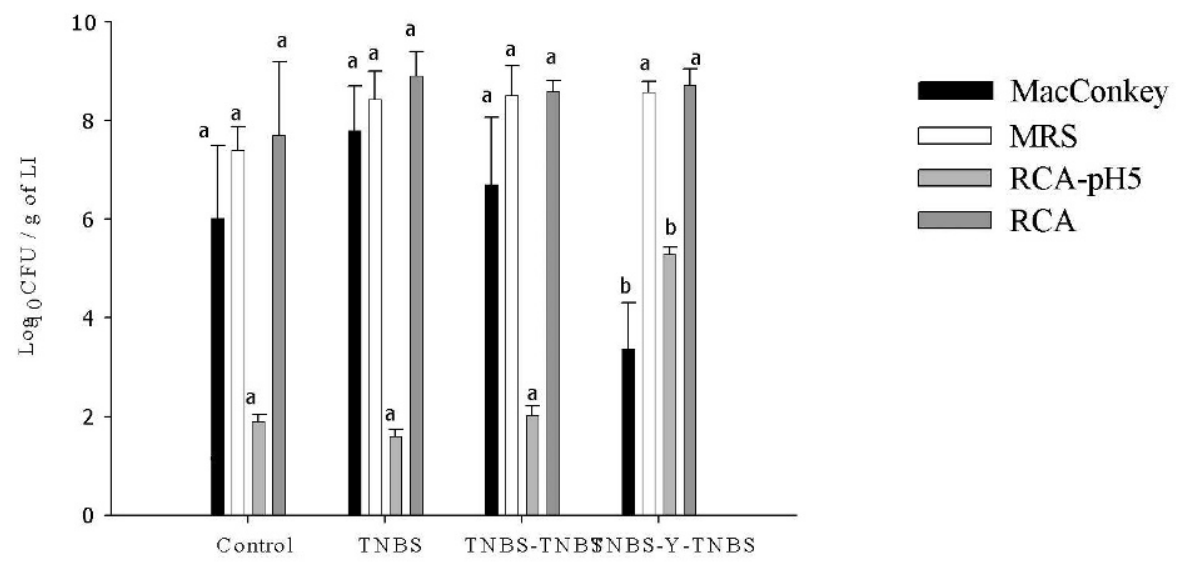

B)

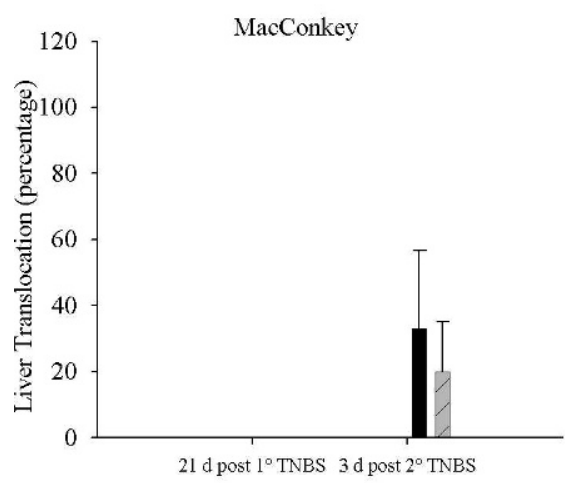

C)

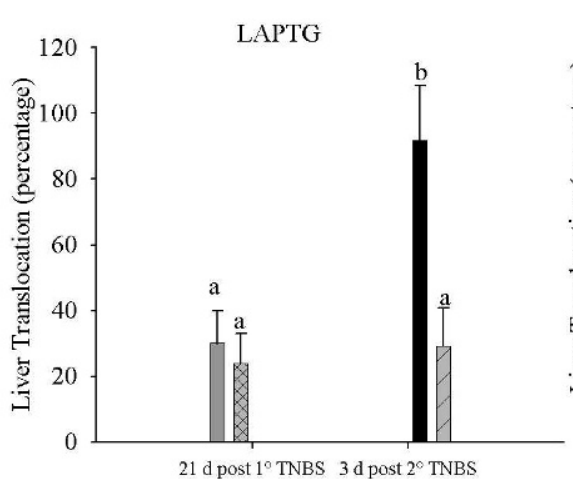

D)

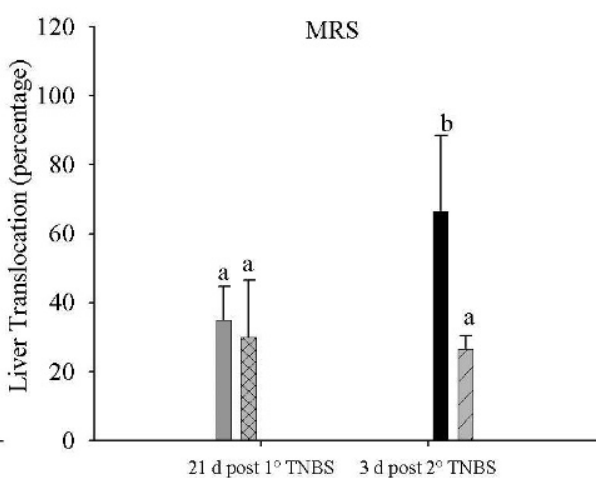

TNBS

FIGURE 5. Effect of yoghurt feeding and TNBS-TNBS-induced recurrent intestinal inflammation on the microbiota of the large intestine and on percentage of bacteria translocated to the liver. Results for microbiota in the large intestine (LI) are expressed as means \pm SD log CFU per gram of LI. (A) Samples were taken at the beginning of the remission period for the control group and for the mice inoculated with TNBS that recovered their body weight (TNBS group) and at the end of this period, i.e., the day of the second TNBS inoculation (TNBS-TNBS and TNBS-yoghurt-TNBS groups). Severity of recurrent TNBS-induced colitis in mice was analyzed based on the percentage of mice in which bacteria were translocated to the liver. Mice from the TNBS group (solid bars) and the TNBS-yoghurt group (shaded bars) were evaluated on the day of the second TNBS inoculation. Mice from the TNBS-TNBS group (solid bars) and the TNBS-yoghurt-TNBS group (diagonal lined bars) were evaluated 3 days after the second TNBS inoculation. The media used were MacConkey agar for enterobacteria (B), LAPTg agar (peptone, tryptone, Tween 80, and glucose) for total lactic acid bacteria (C), and MRS for lactobacilli (D). Values are the means $\pm S D$ of results for 15 mice from three separate experiments. Means without a common letter differ significantly (P $<0.05)$.

mice without inflammation (Fig. 2B). Thus, TLR9 could be implicated in the protective effect of our test yoghurt against TNBS-induced inflammation, in agreement with similar results obtained by other authors in models of inflammation with TNBS-induced and spontaneous colitis $(31,32)$. In another intestinal inflammation model, probiotics or their DNA inhibited the inflammatory response mediated by macrophages, with the production of type I IFN-induced TLR9 (20).

We also investigated the release of cytokines into fluids in the large intestine. In our previous studies, the test yoghurt induced a regulatory immune response with increases of $\mathrm{IL}-10^{+}$cells and decreases of $\mathrm{IL}-17^{+}$cells in the lamina propria of the large intestine (6). We also observed that IFN $\gamma^{+}$cells were increased in mice with and without yoghurt administration, which led us to investigate whether IFN $\gamma$ was being released in the intestinal fluid of mice from the various experimental groups. In the present study, the inflammation control group had increased concentrations of IFN $\gamma$ in the two last samples taken, whereas the mice fed continuously with yoghurt did not, even after TNBS inoculation (Fig. 3A). This finding and that of increased levels of IL-10 in mice fed yoghurt without TNBS (Fig. 3B) suggest that the administration of yoghurt maintained an anti-inflammatory state in the intestine, which was related to the effect observed in the TNBS-induced inflammation model.

Effect of yoghurt administration on the prevention of recurrent intestinal inflammation. Because acute intestinal inflammation remission is often followed by recurrent inflammation episodes, we investigated whether 

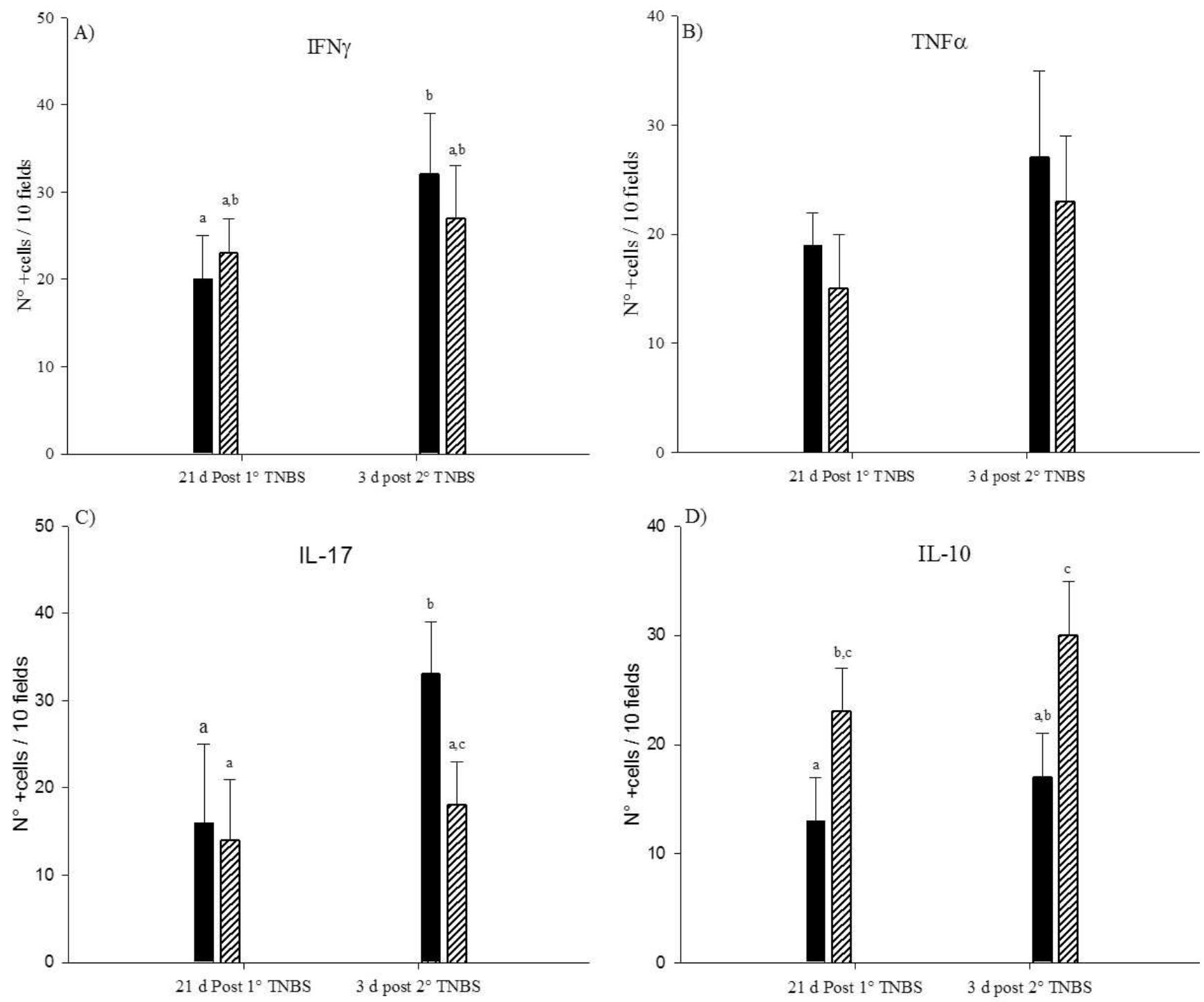

\section{TNBS WID TNBS-Y}

TNBS-TNBS

\section{ZII TNBS-Y-TNBS}

FIGURE 6. Study of cytokine-positive cells in sections of the large intestine of mice. Positive cells for each cytokine were counted in histological sections from large intestine of the TNBS group (solid bars), the TNBS-yoghurt group (diagonal lined bars), the TNBS-TNBS group (solid bars), and the TNBS-yoghurt-TNBS group (diagonal lined bars). Values are the means \pm SD of results for 15 mice from three separate experiments. Means without a common letter differ significantly $(\mathrm{P}<0.05)$.

the consumption of the test yoghurt during the remission period could prevent or attenuate the recurrent inflammation in a TNBS-induced inflammation recurrence model.

The administration of yoghurt for 3 weeks between the two TNBS inoculations reduced the weight loss and prevented the mortality ( 3 to $8 \%$ ) due to the recurrent intestinal inflammation compared with the control mice (TNBS-TNBS group) (Fig. 4A). The mortality rate observed in the control group was associated with a significant loss of body weight and high levels of inflammation, as indicated by intestinal histological changes. This group of mice had severe mucosal damage associated with the influx of immune cells in the intestinal mucosa and submucosa, loss of crypts, and necrosis (Fig. 4D). The highest scores for colon damage were obtained 3 days after the second TNBS administration $(5.3 \pm 0.7)$. The inflammation scores for colon damage obtained from animals fed with yoghurt in the remission period (TNBS-yoghurt-TNBS group) remained similar to control values in both samples taken, $1.1 \pm 0.3$ on the day of the second TNBS inoculation (Fig. 4C) and $1.4 \pm 0.63$ days later (Fig. 4E).

The study of the intestinal microbiota revealed that the mice fed with yoghurt during the remission period had higher populations of the beneficial bacterium Bifidobacterium and fewer enterobacteria (Fig. 5A). This result agrees with those obtained with other probiotic fermented milk products during immune system maturation in mice (7) and in acute IBD cases, in which maintenance of the beneficial balance of the intestinal microbiota could be one of the mechanisms by which yoghurt exerts its antiinflammatory effect (6).

Bacterial translocation to the liver was not observed after continuous yoghurt feeding, 21 day after the first TNBS inoculation, indicating that the yoghurt by itself did 
not induce inflammation and prevented spread of bacteria to other organs. The percentage of mice with bacterial translocation to the liver 3 days after the second TNBS inoculation was higher in the control group for recurrent inflammation (TNBS-TNBS group) than in the group fed with yoghurt during the remission period (TNBS-yoghurtTNBS group, Fig. 5B through 5D).

The cytokine-producing cells also were analyzed to determine whether the anti-inflammatory effect of the test yoghurt prevented recurrence of the inflammation. Mice given yoghurt during the remission period did not have higher numbers of cells that produced IFN $\gamma, \mathrm{TNF} \alpha$, and IL-17, cytokines that were increased in the tissues from mice with recurrent inflammation (TNBS-TNBS group, Fig. 6). IL-17 is one of the principal cytokines involved in the development of IBD (3), and in animals given the test yoghurt the number of IL-17-producing cells decreased even after TNBS inoculation (Fig. 6C).

These results and the lack of bacterial translocation to the liver indicate that the test yoghurt prevented the recurrence of the inflammation and agree with the histological observations of no inflammation in the mice fed yoghurt.

The anti-inflammatory effect of yoghurt administration also was verified with the study of IL-10-producing cells (Fig. 6D). The number of these cells increased significantly after yoghurt was given and the numbers continued to increase after the second TNBS inoculation, indicating that the regulatory effect of yoghurt was maintained. These results are similar to those obtained with a probiotic mixture (VSL\#3); administration of VSL\#3 during the remission period decreased the severity of colitis through its ability to induce an immunoregulatory response mediated by transforming growth factor $\beta$ and IL-10 (9).

In the present work, our test yoghurt exerted a beneficial effect against acute intestinal inflammation by regulating the populations of CD4 and CD8 $\mathrm{T}$ cells and modulating the expression of TLRs with decreases of TLR4 and increases of TLR9. Yoghurt administration also maintained an anti-inflammatory state in the intestine, with increased levels of IL-10 in the intestinal fluid. The antiinflammatory effect of this yoghurt also was found in a recurrent inflammation model in which yoghurt administration during the remission phase prevented recurrent inflammation. This effect was mediated mainly by increasing IL-10 and by causing beneficial changes in the intestinal microbiota, with increases in the populations of bifidobacteria. The exact role of bifidobacteria in the antiinflammatory effect of probiotics or fermented milk products is unknown, and studies are being performed to establish the scientific basis of the beneficial effect of bifidobacteria for mitigating the intestinal inflammatory process. The profile of cytokines observed in the mice fed the test yoghurt leads us to suggest that the same antiinflammatory effect could be obtained by modifying the ratio between IL-17 and IL-10, which increases during the inflammatory process. A modulation of two T-cells subtypes, Th17 and Treg, may be involved. However, because of previous results for mice fed with the same test yoghurt in which no increases of $\mathrm{CD} 4 \mathrm{CD} 25^{+}$cells were observed and findings of the present study in which no increase in $\mathrm{CD} 4{ }^{+}$cells was observed, we cannot discard the possibility that other immune cells could be responsible for the increased IL-10 production. A specific study of different T-lymphocyte subtypes (Th1, Th2, Th17, and Treg), macrophages, and dendritic cells and their relationship to IL-10 production is currently underway.

\section{ACKNOWLEDGMENTS}

This work was financially supported by Agencia Nacional de Promoción Científica y Tecnológica (FONCYT, PICT 05/33213), Consejo de Investigación de la Universidad Nacional de Tucumán, and Consejo Nacional de Investigaciones Científicas y Tecnológicas, Argentina.

\section{REFERENCES}

1. Akhtar, M., J. L. Watson, A. Nazli, and D. M. McKay. 2003. Bacterial DNA evokes epithelial IL-8 production by a MAPK-dependent, NFkappaB-independent pathway. FASEB J. 17:1319-1321.

2. Ameho, C. K., A. A. Adjei, E. K. Harrison, K. Takeshita, T. Morioka, Y. Arakaki, E. Ito, I. Suzuki, A. D. Kulkarni, A. Kawajiri, and S. Yamamoto. 1997. Prophylactic effect of dietary glutamine supplementation on interleukin 8 and tumour necrosis factor alpha production in trinitrobenzene sulphonic acid induced colitis. Gut 41: 487-493.

3. Brand, S. 2009. Crohn's disease: Th1, Th17 or both? The change of a paradigm: new immunological and genetic insights implicate Th17 cells in the pathogenesis of Crohn's disease. Gut 58:11521167.

4. Cong, Y., C. T. Weaver, A. Lazenby, and C. O. Elson. 2002. Bacterial-reactive $\mathrm{T}$ regulatory cells inhibit pathogenic immune responses to the enteric flora. J. Immunol. 169:6112-6119.

5. Danese, S., M. Sans, and C. Fiocchi. 2004. Inflammatory bowel disease: the role of environmental factors. Autoimmun. Rev. 3:394 400 .

6. de Moreno de LeBlanc, A., S. Chaves, and G. Perdigón. 2009. Effect of yoghurt on the cytokine profile using a murine model of intestinal inflammation. Eur. J. Inflamm. 7:97-109.

7. de Moreno de LeBlanc, A., C. A. Dogi, C. M. Galdeano, E. Carmuega, R. Weill, and G. Perdigón. 2008. Effect of the administration of a fermented milk containing Lactobacillus casei DN-114001 on intestinal microbiota and gut associated immune cells of nursing mice and after weaning until immune maturity. $B M C$ Immunol. 9:27.

8. de Moreno de LeBlanc, A., and G. Perdigón. 2004. Yogurt feeding inhibits promotion and progression of experimental colorectal cancer. Med. Sci. Monit. 10:BR96-BR104.

9. Di Giacinto, C., M. Marinaro, M. Sanchez, W. Strober, and M. Boirivant. 2005. Probiotics ameliorate recurrent Th1-mediated murine colitis by inducing IL-10 and IL-10-dependent TGF-betabearing regulatory cells. J. Immunol. 174:3237-3246.

10. Food and Agriculture Organization and World Health Organization. 2001. Evaluation of health and nutritional properties of powder milk and live lactic acid bacteria. Food and Agriculture Organization of the United Nations and World Health Organization expert consultation report. Available at: http://www.fao.org/ag/agn/agns/micro_probiotics_ en.asp.

11. Fujimori, S., A. Tatsuguchi, K. Gudis, T. Kishida, K. Mitsui, A. Ehara, T. Kobayashi, Y. Sekita, T. Seo, and C. Sakamoto. 2007. High dose probiotic and prebiotic cotherapy for remission induction of active Crohn's disease. J. Gastroenterol. Hepatol. 22:1199-1204.

12. Fukata, M., and M. T. Abreu. 2007. TLR4 signalling in the intestine in health and disease. Biochem. Soc. Trans. 35:1473-1478.

13. Galdeano, C. M., A. de Moreno de LeBlanc, E. Carmuega, R. Weill, and G. Perdigón. 2009. Mechanisms involved in the immunostimulation by probiotic fermented milk. J. Dairy Res. 76:446-454.

14. Galdeano, C. M., A. de Moreno de LeBlanc, G. Vinderola, M. E. Bonet, and G. Perdigón. 2007. Proposed model: mechanisms of 
immunomodulation induced by probiotic bacteria. Clin. Vaccine Immunol. 14:485-492.

15. Heilpern, D., and A. Szilagyi. 2008. Manipulation of intestinal microbial flora for therapeutic benefit in inflammatory bowel diseases: review of clinical trials of probiotics, pre-biotics and synbiotics. Rev. Recent Clin. Trials 3:167-184.

16. Ishihara, S., M. A. Rumi, C. F. Ortega-Cava, H. Kazumori, Y. Kadowaki, N. Ishimura, and Y. Kinoshita. 2006. Therapeutic targeting of toll-like receptors in gastrointestinal inflammation. Curr. Pharm. Des. 12:4215-4228.

17. Isono, A., T. Katsuno, T. Sato, T. Nakagawa, Y. Kato, N. Sato, G. Seo, Y. Suzuki, and Y. Saito. 2007. Clostridium butyricum TO-A culture supernatant downregulates TLR4 in human colonic epithelial cells. Dig. Dis. Sci. 52:2963-2971.

18. Jonuleit, H., E. Schmitt, M. Stassen, A. Tuettenberg, J. Knop, and A. H. Enk. 2001. Identification and functional characterization of human $\mathrm{CD} 4(+) \mathrm{CD} 25(+) \mathrm{T}$ cells with regulatory properties isolated from peripheral blood. J. Exp. Med. 193:1285-1294.

19. Kappeler, A., and C. Mueller. 2000. The role of activated cytotoxic T cells in inflammatory bowel disease. Histol. Histopathol. 15:167172.

20. Katakura, K., J. Lee, D. Rachmilewitz, G. Li, L. Eckmann, and E. Raz. 2005. Toll-like receptor 9-induced type I IFN protects mice from experimental colitis. J. Clin. Invest. 115:695-702.

21. Langrish, C. L., Y. Chen, W. M. Blumenschein, J. Mattson, B. Basham, J. D. Sedgwick, T. McClanahan, R. A. Kastelein, and D. J. Cua. 2005. IL-23 drives a pathogenic T cell population that induces autoimmune inflammation. J. Exp. Med. 201:233-240.

22. Lee, J., D. Rachmilewitz, and E. Raz. 2006. Homeostatic effects of TLR9 signaling in experimental colitis. Ann. NY Acad. Sci. 1072: 351-355.

23. Leon, F., L. E. Smythies, P. D. Smith, and B. L. Kelsall. 2006. Involvement of dendritic cells in the pathogenesis of inflammatory bowel disease. Adv. Exp. Med. Biol. 579:117-132.

24. Lorea Baroja, M., P. V. Kirjavainen, S. Hekmat, and G. Reid. 2007. Anti-inflammatory effects of probiotic yogurt in inflammatory bowel disease patients. Clin. Exp. Immunol. 149:470-479.

25. Macfarlane, S., H. Steed, and G. T. Macfarlane. 2009. Intestinal bacteria and inflammatory bowel disease. Crit. Rev. Clin. Lab. Sci. 46:25-54.

26. Neurath, M. F., I. Fuss, B. L. Kelsall, D. H. Presky, W. Waegell, and W. Strober. 1996. Experimental granulomatous colitis in mice is abrogated by induction of TGF-beta-mediated oral tolerance. J. Exp. Med. 183:2605-2616.

27. Neut, C., P. Bulois, P. Desreumaux, J. M. Membre, E. Lederman, L. Gambiez, A. Cortot, P. Quandalle, H. van Kruiningen, and J. F. Colombel. 2002. Changes in the bacterial flora of the neoterminal ileum after ileocolonic resection for Crohn's disease. Am. J. Gastroenterol. 97:939-946.
28. Obermeier, F., N. Dunger, U. G. Strauch, C. Hofmann, A. Bleich, N. Grunwald, H. J. Hedrich, E. Aschenbrenner, B. Schlegelberger, G. Rogler, J. Scholmerich, and W. Falk. 2005. CpG motifs of bacterial DNA essentially contribute to the perpetuation of chronic intestinal inflammation. Gastroenterology 129:913-927.

29. Pimentel-Nunes, P., J. B. Soares, R. Roncon-Albuquerque, Jr., M. Dinis-Ribeiro, and A. F. Leite-Moreira. 2010. Toll-like receptors as therapeutic targets in gastrointestinal diseases. Expert Opin. Ther. Targets 14:347-368.

30. Podolsky, D. K. 2002. Inflammatory bowel disease. N. Engl. J. Med. 347:417-429.

31. Rachmilewitz, D., F. Karmeli, K. Takabayashi, T. Hayashi, L. LeiderTrejo, J. Lee, L. M. Leoni, and E. Raz. 2002. Immunostimulatory DNA ameliorates experimental and spontaneous murine colitis. Gastroenterology 122:1428-1441.

32. Rachmilewitz, D., K. Katakura, F. Karmeli, T. Hayashi, C. Reinus, B. Rudensky, S. Akira, K. Takeda, J. Lee, K. Takabayashi, and E. Raz. 2004. Toll-like receptor 9 signaling mediates the antiinflammatory effects of probiotics in murine experimental colitis. Gastroenterology 126:520-528.

33. Ruddy, M. J., G. C. Wong, X. K. Liu, H. Yamamoto, S. Kasayama, K. L. Kirkwood, and S. L. Gaffen. 2004. Functional cooperation between interleukin-17 and tumor necrosis factor-alpha is mediated by CCAAT/enhancer-binding protein family members. J. Biol. Chem. 279:2559-2567.

34. Schultz, M., and A. L. Lindstrom. 2008. Rationale for probiotic treatment strategies in inflammatory bowel disease. Expert Rev. Gastroenterol. Hepatol. 2:337-355.

35. Sokol, H., B. Pigneur, L. Watterlot, O. Lakhdari, L. G. BermudezHumaran, J. J. Gratadoux, S. Blugeon, C. Bridonneau, J. P. Furet, G. Corthier, C. Grangette, N. Vasquez, P. Pochart, G. Trugnan, G. Thomas, H. M. Blottiere, J. Dore, P. Marteau, P. Seksik, and P. Langella. 2008. Faecalibacterium prausnitzii is an anti-inflammatory commensal bacterium identified by gut microbiota analysis of Crohn disease patients. Proc. Natl. Acad. Sci. USA 105:16731-16736.

36. Strober, W., I. Fuss, and P. Mannon. 2007. The fundamental basis of inflammatory bowel disease. J. Clin. Invest. 117:514-521.

37. Takaishi, H., T. Matsuki, A. Nakazawa, T. Takada, S. Kado, T. Asahara, N. Kamada, A. Sakuraba, T. Yajima, H. Higuchi, N. Inoue, H. Ogata, Y. Iwao, K. Nomoto, R. Tanaka, and T. Hibi. 2008. Imbalance in intestinal microflora constitution could be involved in the pathogenesis of inflammatory bowel disease. Int. J. Med. Microbiol. 298:463-472.

38. Tamboli, C. P., C. Neut, P. Desreumaux, and J. F. Colombel. 2004. Dysbiosis in inflammatory bowel disease. Gut 53:1-4.

39. Vizoso Pinto, M. G., M. Rodriguez Gomez, S. Seifert, B. Watzl, W. H. Holzapfel, and C. M. Franz. 2009. Lactobacilli stimulate the innate immune response and modulate the TLR expression of HT29 intestinal epithelial cells in vitro. Int. J. Food Microbiol. 133: 86-93. 